\title{
Exploring Feelings of Worry and Sources of Stress during COVID-19 Pandemic among Parents of Children with Disability: A Sample from Arab Countries
}

\author{
Faisal Abdelfattah ${ }^{1, *} \mathbb{1}$, Ahmad Rababah ${ }^{1}$, Ibrahim Alqaryouti ${ }^{2}$, Zaidan Alsartawi ${ }^{3}$, Dareen Khlaifat ${ }^{1}$ \\ and Abdullah Awamleh ${ }^{1}$ \\ 1 College Education, Imam Abdulrahman Bin Faisal University, Dammam 31441, Saudi Arabia; \\ arababah@iau.edu.sa (A.R.); daaskhlaifat@iau.edu.sa (D.K.); aawamleh@iau.edu.sa (A.A.) \\ 2 College of Education, Sultan Qaboos University, Muscat OM 123, Oman; ibrahimqa@squ.edu.om \\ 3 College of Education, King Saud University, Riyadh 11451, Saudi Arabia; zaqasem@ksu.edu.sa \\ * Correspondence: faabdelfattah@iau.edu.sa
}

Citation: Abdelfattah, F.; Rababah, A.; Alqaryouti, I.; Alsartawi, Z.; Khlaifat, D.; Awamleh, A. Exploring Feelings of Worry and Sources of Stress during COVID-19 Pandemic among Parents of Children with Disability: A Sample from Arab Countries. Educ. Sci. 2021, 11, 216. https://doi.org/10.3390/ educsci11050216

Academic Editors: Tiina Itkonen and Henri Pesonen

Received: 5 April 2021

Accepted: 1 May 2021

Published: 4 May 2021

Publisher's Note: MDPI stays neutral with regard to jurisdictional claims in published maps and institutional affiliations.

Copyright: (c) 2021 by the authors. Licensee MDPI, Basel, Switzerland. This article is an open access article distributed under the terms and conditions of the Creative Commons Attribution (CC BY) license (https:// creativecommons.org/licenses/by/ $4.0 /)$.

\begin{abstract}
The study sought to explore feelings of worry and sources of stress-affected parents of children with disabilities, as well as describing the negative feelings and how resources helped them overcome stress due to the outbreak of the Coronavirus. Furthermore, we sought to assess the level of general satisfaction with the services they have obtained remotely. Methodology: A sample of 623 parents of children with disabilities filled out an electronic self-report questionnaire during the period June 4th to June 20th, 2020. Results: The parents reported a high level of worry regarding the possibility of their child getting infected. Parents continue to worry about losing their child's care and treatment. Parents who hold a bachelor's degree feel the sources of stress at a higher level compared to parents with lower than high school education. A proportion of $59 \%$ of parents reported not receiving services from special education centers during the pandemic, and $41 \%$ of parents were satisfied with the services provided by the center of special education. Parents with a bachelor's degree or higher were less satisfied with the center's services. Parents with a higher qualification than secondary school use several sources to overcome the pressure associated with educating a child with a disability. Conclusion: Mental health fears were associated with pandemic restrictions. The study recommends special education centers implement strategies that support parents with special education children.
\end{abstract}

Keywords: mental health; satisfaction; children with disabilities; parents; COVID-19

\section{Introduction}

The novel coronavirus (COVID-19) pandemic has affected millions of people globally as case numbers are estimated to reach 9 million cases from March 2020 to June 2020, with a death count of around 1 million. Simultaneously, the Arab world faced various pressures, and despite the vast differences in the health systems and available resources to face the pandemic between the 22 Arab countries, the region remains unprepared to deal with the effects of the COVID-19 pandemic.

The initial spread of the pandemic was limited in the Arab world compared to other areas. However, the strong geopolitical and business relations the Middle East holds with Europe, North America, and East Asia have eventually eased the spread of the COVID-19 pandemic. The World Health Organization [1] issued a warning in March 2020 stating that the pandemic spread has not yet reached its peak in the Middle East and North Africa and urging countries to prepare for the anticipated increase in the spread. The human relations between the Arab world and the disease hotspots have facilitated the rapid spread of COVID-19 in the area. The high population density in certain Arab countries has further contributed to the spread, in addition to the scarcity of the tool kits necessary to detect COVID-19 cases and consequently treat them. 
Arab governments took the necessary actions for the response to the COVID-19 spread, including social isolation measures, border closure, the cancelation of the flights, issuing stay-at-home orders, closing worship places, suspension of work permits for foreigners, and ordering tourists to return to their countries. Different forms of curfew were implemented in Arab countries. These included night curfews beginning mid-March in Tunisia, Egypt, and Saudi Arabia, in addition to around-the-clock curfews in Jordan and Iraq. Additionally, most countries suspended or reduced most economic activities, including the closure of retail stores, educational centers, workplaces, recreational events, and non-essential services [2].

The consequent closing of schools in March meant difficulties in delivering therapy services virtually. One of schools' major roles in traditional circumstances before coronavirus pandemic was to provide various services for children with disabilities (e.g., Individualized Education Program (IEP), speech-language therapy, physical therapy, occupational therapy, counseling, etc.). Special education centers have provided these services to children with disabilities in person for years. Hence, after special education centers are closed, therapists and teachers are unable to provide appropriate therapy and education to children.

The COVID-19 pandemic has affected families and parents, as they faced challenges in educating their children remotely as mandated by the ministries of education, despite the preferences of face-to-face education by parents. Deficiencies in online education methods have led to resistance to this form of education by parents. In addition to the lack of time and sufficient technical skills necessary to support the education of their children, there was also an inability of children to self-organize and manage their education. Therefore, untrained parents found it difficult to implement remote learning methods [3].

Children with disabilities are among the at-risk groups according to the effects caused by the pandemic. Their cognitive and intellectual disabilities limit ability to comprehend the warnings issued to help them protect themselves from contracting and spreading the COVID-19 infection [4]. Moreover, certain disabilities such as Autism Spectrum Disorder (ASD) require therapeutic interventions and services provided by specialists and, therefore, require being present in specialized centers [5].

The social distancing and quarantine measures have led to the suspension of services, support, and official and non-official sponsorship provided to children with disabilities. For example, educational institutions and special education centers closed their doors across all educational levels, presenting a challenge for families with disabled children. Thus, negative psychological emotions of stress and irritability have emerged among families. Parents and caregivers needed more services to compensate for the center services during such closures.

Considering the parents' lack of knowledge of appropriate ways to deal with a child with a disability, the need for psychological and social support emerges, as does the need for various services essential for facing and adapting to new circumstances and providing the requirements for child development and all aspects of growth. In this regard, educators stressed the importance of teachers and specialists reaching beyond the walls of the classroom by providing support to parents and meeting their needs on how to manage everyday situations in which the child exhibits behavioral problems and manifestations of maladjustment [6-8]. As a result, reports from some countries around the world with similar COVID-19 situations showed a high degree of certain psychological disorders such as discomfort, depression, and anxiety as well as the continued emergence of post-traumatic stresses that result from quarantine, many of which persist for long periods [9].

People differ in their behavior according to their living circumstances. For example, some individuals show an emotional state that varies in intensity and frequency in response to a situation. Temporary anxiety is seen as an emotional state that manifests in response to a specific situation that the individual is going through. The intensity and fluctuations of state-of-anxiety change in terms of its emergence according to the situation. Moreover, stress is seen as an emotional and behavioral response to some unpleasant conditions expe- 
rienced by an individual, which negatively affects the performance of their life functions and behavior with those around them [10].

Despite numerous studies that discuss anxiety among individuals or medical workers during the Corona pandemic and the suspension of regular activities, populations in need of special care and rehabilitation have not been adequately studied under the conditions of their stay at home and inability to access rehabilitation centers. The latter follows from the closure of rehabilitation centers as well as the prohibition of movement between places except for the most urgent necessities and medical emergencies. The responsibility of caring for, training, rehabilitating, and educating the child rests on the shoulders of the parents [11].

Parents' feelings of annoyance are generated as a psychological response to the challenging circumstances they live in. Due to the difficulty of dealing with children, the emergence of unwanted forms of behavior and emotion, especially among children with disabilities, the level of stress increases in cases where there is a child with a disability in the family. The type and severity of stress vary according to the type of child's disability, their physical condition, and their level of development, in addition to the financial and psychological problems that the guardian is going through and the social circumstances surrounding the family [12].

The theoretical framework for stress identifies the presence of situational factors that increase stress among parents to a higher level than normal, especially among parents of children with disabilities. Family problems between spouses, feelings of loneliness, and distress emerge highly compared to families without a child with a disability. Children, on the other hand, are affected by how parents respond to stress and manifest weakness in acquiring self-control skills and strategies for coping with stress; disturbing behavior that appears in the form of anxiety, sadness, social withdrawal, and psychological fears may emerge in addition to unwanted responses to the surroundings, such as aggressive behavior toward others [13].

Multiple studies and surveys conducted during previous pandemics or since the beginning of the COVID-19 pandemic have discussed the psychological manifestations among general members of society, without adequate examination of these manifestations among special education populations. Parents of children face additional new challenges that go beyond what the pandemic imposed upon community members at large [14]. Detecting the feelings of distress and anxiety that affected the parents will aid and direct support to mitigate such feelings, consequently achieving a higher level of psychological adjustment and improving the services directed to them.

\section{Previous Studies}

The new circumstances of quarantine and the closure of special education centers resulted from the spread of the coronavirus and the associated preventive measures have led to the emergence of varying levels of stress and worry among parents of children with disabilities.

Stress and fear experienced by parents of children with disabilities during the Covid-19 pandemic. In the psychosocial and behavioral context of the COVID-19 pandemic on special groups, Lee et al. (2021) discussed parent-child dynamics during school closures associated with COVID-19, based on a cross-sectional survey. The data were collected about five weeks after the WHO declared the Coronavirus a pandemic. The participants consisted of 405 parents from all over the United States who had at least one child with a disability. The results showed that most families $78 \%$ were educating their children at home due to the COVID-19 pandemic. Two of five parents met the PHQ-8 criteria for severe depression or moderate or severe anxiety, and parents who experienced severe or severe depression had feelings of stress negatively associated with a parent's perceived preparation for homeschooling. Parents with moderate or severe anxiety reported that their child also experienced anxiety. Feelings of parental stress were positively associated with higher levels of anxiety experienced by the child. The analysis of open-question answers reported 
that school closures were a major disruption, followed by a lack of physical activity and social isolation [15].

Thorell et al. (2021) examined parental experiences of homeschooling during the COVID-19 pandemic in families with neurodevelopmental disorders, specifically Attention Deficit Hyperactivity Disorder (ADHD) or Autism Spectrum Disorders (ASD), as well as those without a child with a mental health condition across Europe. The study included 6720 parents recruited through schools, patient organizations, and social media platforms (2002 parents with a child with a mental health condition and 4718 without) from seven European countries: the UK, Sweden, Spain, Belgium, the Netherlands, Germany, and Italy. Many parents reported negative effects of homeschooling for themselves and their child, and many found homeschooling to be of poor quality, with insufficient support from schools. Parents also reported increased levels of stress, worry, social isolation, and domestic conflict. A small number of parents reported increased parental alcohol/drug use, and some differences were found between countries [16].

Ren et al. (2020) also examined the state of anxiety among parents of children with disabilities during the Coronavirus (COVID-19) epidemic and the effect of parental stress, social support, and other relevant variables on parental feelings of anxiety. Responses from 1451 parents were collected online using questionnaires on psychological and behavioral domains of children and parents during the epidemic. The results indicated that parents of children with disabilities had suffered from psychological and behavioral problems, parenting pressures, and lack of social support, which affected their concern about their situation. The monthly income of the family, the educational background of the parents, and the type of disability of their children increased parental anxiety during the outbreak of COVID-19 [11]. Concerning the feelings of families, Alhuzimi (2021) examined the stress and emotional well-being of 150 parents of children with autism in Saudi Arabia during the COVID-19 pandemic. The results revealed that the age and gender of the child who has autism, and the severity of his symptoms had a significant impact on the emergence of parental stress and low emotional well-being. Feelings of parental stress increased, and the amount of emotional well-being decreased according to the frequency and benefit of child support received during the pandemic and the change in the severity of autistic behaviors in children. Parental stress also harms the emotional well-being of parents [17].

Regarding the area of parent mental health, Chen et al. (2020) evaluated a mental health survey of parents of children with disabilities during the COVID-19 pandemic, which included responses from 1450 parents. The results showed that parents of children with ASD are more likely to have mental health problems compared to parents of children with intellectual, visual, or auditory disabilities. The common factors predicting the level of mental health of all parents were the behavioral problems of the children and the psychological requirements of the parents [18]. Colizzi et al. (2020) conducted a study to predict the impact of children's demographic and clinical characteristics before the corona pandemic on mental health and to determine their needs to deal with the emergency. Five hundred and twenty-seven parents of children with ASD responded to an electronic questionnaire. The findings showed that challenges appeared in approximately $94 \%$ of families and that these caused more difficulty for them in dealing with daily activities, in addition to difficulty acting during free time for $78 \%$ of families [19].

Kucharewucz and Wieteska (2019) conducted a study in Poland to explore the psychological needs of families of children with intellectual disabilities and the role of social support in securing their mental health. To achieve the aim of the study, a qualitative approach based on content analysis was used. The results showed that the psychological needs of families of children with intellectual disabilities were evident. Such parents need support from surrounding individuals and society to ensure the mental health of the family and to educational and counseling services to enable them to deal with children with disabilities [20]. Van Esch et al. (2018) conducted a study in Belgium to determine the psychological and social needs of families of adolescent students with ASD by interviewing 17 parents. The results revealed that the psychological and social support that families 
required were adequate information about the condition of their children, financial support to secure the expenses of services provided to their children, appropriate services for their children, support and encouragement, and coordination with the school and professional bodies for effective communication between them, counseling, and guidance [21].

The conclusion from the previous studies leads us to the fact that many psychological pressures occur in families with children with disabilities, as well as to the fact that the needs emerged with that disability. Parents also need continuous psychological support. There has not been sufficient coverage of studies identifying the feelings of distress experienced by parents of children with disabilities in Arab society nor exploring the sources of stress and ways to overcome it.

\subsection{The Significance of the Study}

The study contributes to deepening our understanding of the impact of the pandemic on parents of children with disabilities, thus paving the way for structuring strategies and guiding special education centers and specialists when dealing with parents of children with disabilities. Findings will help to develop support programs and services for families in Arab countries.

\subsection{The Problem Statement}

Essentially, the Corona pandemic remains affecting the world: Research is still proceeding to search for ways to help alleviate its consequences on public life and society. Given that families of children with disabilities are one of the groups that need constant support and assistance, the problem of the current study is to identify the concerns among parents and the change of feelings from the beginning of the pandemic until the period of conducting the study. Knowing sources of stress that affected parents of children with disabilities during the Corona pandemic and the sources used to overcome pressure are vital for administrators to create better support for families. After considering the level of parents' evaluation of the services of special education centers, the study specifically answers the following research questions:

1. What level of worry did parents of children with disabilities feel at the beginning and during the Corona pandemic?

2. What are the sources of stress that affected parents in educating and training a child with disabilities at home due to the spread of the coronavirus?

3. What are the sources that the parents used to overcome the stress associated with the education and training of a child with disabilities at home during the spread of the coronavirus?

4. How do parents evaluate the services they received from the special education centers during the corona pandemic?

\section{Method}

\subsection{Participants}

The study population comprised parents of children with disabilities who provided home care for their children during the closure of special education centers due to the corona pandemic. The snowball sampling was followed using the social media groups Facebook, WhatsApp, and Twitter in addition to communicating with teachers and specialists of special education centers to pass the link of the electronic questionnaire to the parents. The responses of 623 participants were analyzed, of which women represented $70.8 \%$, as shown in Table 1. 
Table 1. Characteristics of the parents.

\begin{tabular}{|c|c|c|c|c|c|}
\hline $\begin{array}{c}\text { Age } \\
\mathrm{N} \text { (Ratio) }\end{array}$ & $\begin{array}{c}>30 \text { yrs. } \\
108 \text { (17.3) }\end{array}$ & $\begin{array}{c}30-50 \text { yrs. } \\
430(69)\end{array}$ & $\begin{array}{l}<50 \text { yrs. } \\
85 \text { (13.6) }\end{array}$ & & \\
\hline $\begin{array}{l}\text { Academic level } \\
\text { N (Ratio) }\end{array}$ & $\begin{array}{l}\text { Illiterate } \\
13(2.1)\end{array}$ & $\begin{array}{l}\text { Less than } \\
\text { secondary } \\
211(33.9)\end{array}$ & $\begin{array}{l}\text { Diploma } \\
93(14.9)\end{array}$ & $\begin{array}{c}\text { BA } \\
261(41.9)\end{array}$ & $\begin{array}{c}\text { Postgrad. } \\
45(7.2)\end{array}$ \\
\hline $\begin{array}{l}\text { Parents' job } \\
\text { N (Ratio) }\end{array}$ & $\begin{array}{c}\text { Employee } \\
25(40.3)\end{array}$ & $\begin{array}{c}\text { Free work } \\
28(4.5)\end{array}$ & $\begin{array}{c}\text { Retired or } \\
\text { without a job } \\
103(16.5)\end{array}$ & $\begin{array}{l}\text { Student } \\
12(1.9)\end{array}$ & $\begin{array}{c}\text { Housewife } \\
229(36.8)\end{array}$ \\
\hline $\begin{array}{l}\text { Relationship with } \\
\text { the child } \\
\text { N (Ratio) }\end{array}$ & $\begin{array}{c}\text { Mother } \\
413(66.3)\end{array}$ & $\begin{array}{c}\text { Father } \\
139(22.3)\end{array}$ & $\begin{array}{l}\text { Other relatives } \\
\text { help parents } \\
71(10.14)\end{array}$ & & \\
\hline
\end{tabular}

All participants were parents of children with disabilities from several Arab countries, of which 249 parents responded from Saudi Arabia; 216 from the Sultanate of Oman; 81 from the United Arab Emirates; 28 from Jordan; 27 from Kuwait; and 22 from Bahrain, Qatar, and Palestine.

\subsection{Measures}

The study instrument was designed based on the theoretical literature and previous studies regarding the role of the parents in dealing with a child with a disability at home (Courtenay \& Perera, 2020; Van Esch et al., 2018), and studies related to emotions during the Corona pandemic (Courtenay \& Perera, 2020; Van Esch et al., 2018; Colizzi et al., 2020; and Esentürk, 2020 [22]). The questionnaire was based on the self-report type consisting of 24 statements covering the study domains, in addition to the demographics of the parent and child with a disability, such as a gender, age, academic level, severity, and type of disability. Specifically, the study instrument measures were as follows.

Parent's worry Feelings. Seven statements measure the feelings of worry from the moment the pandemic spread in mid-March 2020 to the study period, approximately 3 months after the outbreak. For example, "What is the level of your concern about your child's loss of care, assistance, and treatment from specialists at the start of the pandemic's spread and the stopping of the center's work?" using a five-point Likert scale 1: Not disturbed to 5: Highly disturbed.

Sources of Stress. Five statements measure the sources of stress due to the stopping of the services of the special education centers. For example, "No outside activities or stimulating activities for my child" using a five-point Likert scale, 1: Strongly disagree to 5: Strongly agree.

Sources to Overcome Pressure. Ten statements representing the sources helped parents with the education and training of a child with a disability at home due to the spread of the coronavirus. For example: "Reading scientific studies, books, or magazines about dealing with a child with a disability" using a five-point Likert scale 1: Never to 5: Always.

Satisfaction of the Services. Two statements measure parents' satisfaction about obtaining services from special education centers. For example: "My child's services received from the center" is evaluated using a five-point Likert scale 1: Not satisfied to 5: Very satisfied.

The statements were constructed after an extensive review of previous studies related to the feelings of parents in general (e.g., [18]) and studies investigating the effects of the corona pandemic $[20,22]$. There was a lack of instruments relevant to the urgent and emerging conditions for assessing parents' needs related to the corona pandemic.

Validity. A committee of six faculty members in universities and specialists in special education centers were asked to review the content of the items, clarity, and ability to measure what it aims. After examining the feedback and making modifications based on the comments from the reviewers, the final questionnaire was electronically distributed. This procedure is considered an indication of the content validity of the instrument.

Reliability. Internal consistency was obtained by Cronbach's alpha as an indicator of reliability. The internal consistency of the parents' worry-feeling scale at the beginning of 
the pandemic was 0.859 , and for the items that measure their worry at the current moment, the time of filling the response was also 0.860; the sources of stress scale was 0.70 , and sources to overcome pressure was 0.861 . These values outline a sufficient indicator of the reliability of the study instrument.

\subsection{Procedures}

Parents' views in this study were surveyed through an electronic questionnaire designed on the JotForm website (https: / / eu.jotform.com, accessed on 3 June 2020). Parents of children with disabilities in several Arab countries were invited to participate in the study. Invitations were sent through the centers' administrations or by communicating with teachers and specialists working in the field of special education. An advertisement was also placed in forums and social media groups concerned with issues of persons with disabilities. The data collection continued for more than two weeks, during the period from 4 June to 20 June 2020. The questionnaire requires less than $15 \mathrm{~min}$ to answer all statements. To confirm the completeness of responses to all the statements, a note "This field is required" appears if the answer is skipped. Upon completion of the response, a message of appreciation was shown to thank the parent for participation in the study.

It was emphasized in the introduction to the questionnaire that participation in the study was completely voluntary and that the parent had the right to withdraw at any moment. It was also indicated that the data of this study were confidential and would be used for scientific research purposes.

Research methodology. The study followed the descriptive methodology to explore the study variables and assess the relationships between them without interfering or controlling any conditions.

\subsection{Statistical Analyses}

Descriptive statistics were calculated for the parents' worry scale items at the beginning of the pandemic and the current period, and a related samples t-test was used to answer the first research question. Proportions and Chi-square were calculated to display the sources of stress, followed by two independent sample-tests to examine differences according to parent's qualification in the second research question. Proportions and Chisquare were calculated to display sources to overcome the pressure as requested in the third research question and level of satisfaction in the fourth research question.

\section{Results}

The results start with summarizing the characteristics of the child with a disability. Of the 623 parents of children with diverse disabilities, 103 indicated intellectual disability (16.5\%), 200 autism (32.1\%), 121 down syndrome (19.4\%), 48 attention deficit hyperactivity $(7.7 \%), 46$ speech and language disorders $(7.4 \%)$, and 105 other disorders (16.9\%). The severity of the disability classification was mild for 153 children (24.6\%), medium for 298 (47.8\%), between severe to very severe for $106(17 \%)$, and do not know for 66 children (10.6\%).

The age of the children: $84.3 \%$ ranged from 1 to 15 years; in addition, $65.5 \%$ were males. When the parent was asked "Can your child express his/her fear?", 263 (42.2\%) responded that their children can do so with words and physical expressions and $44(6.9 \%)$ with words only, while 243 (39\%) with physical expressions only, and $74(11.9 \%)$ cannot express their fear with words or physical expressions. That the mother supervises and trains the child at home most of the time occurred in 507 cases $(81.4 \%)$, while the father supervises and trains less than $47(7.5 \%)$. A brother or sister supervised in 49 cases $(7.9 \%)$; the caretaker supervises the child at a low rate of $20(3.2 \%)$. These ratios could direct the attention of the services provided to parents and activating the father's participation at a higher rate to help the mother in supervising the child with disabilities at home.

Results according to research questions. To address the first research question, "What level of worry did parents of children with disabilities feel at the beginning and during the 
corona pandemic"? Descriptive statistics and two related samples $t$-tests were extracted in

Table 2 for the worry scale at the two occasions.

Table 2. Descriptive statistics and two related samples $t$-test for worry scale.

\begin{tabular}{|c|c|c|c|c|c|c|}
\hline \multirow[b]{2}{*}{$\mathbf{N}$} & \multirow[b]{2}{*}{ Item } & \multicolumn{2}{|c|}{ The Beginning of the Outbreak of the Pandemic } & \multicolumn{2}{|c|}{ Current Period } & \multirow[b]{2}{*}{ Related Samples $t$-Test } \\
\hline & & Mean & SD & Mean & SD & \\
\hline 1 & $\begin{array}{l}\text { How upset are you about } \\
\text { your child's safety in } \\
\text { regards to being infected } \\
\text { with the coronavirus? }\end{array}$ & 3.18 & 1.26 & 3.14 & 1.25 & 1.00 \\
\hline 2 & $\begin{array}{l}\text { How upset are you that } \\
\text { your child cannot get used } \\
\text { to being at home } \\
\text { all the time? }\end{array}$ & 2.91 & 1.32 & 2.71 & 1.32 & $5.55^{*}$ \\
\hline 3 & $\begin{array}{l}\text { What is the level of your } \\
\text { annoyance towards your } \\
\text { child's feeling bored? }\end{array}$ & 3.22 & 1.23 & 3.06 & 1.24 & $3.83 *$ \\
\hline 4 & $\begin{array}{l}\text { How upset are you about } \\
\text { your child's loss of care, } \\
\text { assistance, and treatment } \\
\text { from specialists (special } \\
\text { education specialist, } \\
\text { psychologist, language } \\
\text { specialist ...)? }\end{array}$ & 3.57 & 1.23 & 3.52 & 1.27 & 1.56 \\
\hline 5 & $\begin{array}{l}\text { How upset are you about } \\
\text { not being able to balance } \\
\text { doing your job with caring } \\
\text { for your child at home? }\end{array}$ & 3.12 & 1.37 & 2.94 & 1.36 & $4.76^{*}$ \\
\hline 6 & $\begin{array}{l}\text { What is the level of your } \\
\text { distress about your lack of } \\
\text { self-confidence in providing } \\
\text { psychological and } \\
\text { educational support to } \\
\text { your child? }\end{array}$ & 3.09 & 1.32 & 2.92 & 1.35 & $4.54 *$ \\
\hline 7 & $\begin{array}{l}\text { What is your level of } \\
\text { annoyance that the } \\
\text { coronavirus infection may } \\
\text { be transmitted to } \\
\text { your child? }\end{array}$ & 3.65 & 1.26 & 3.46 & 1.29 & $4.25^{*}$ \\
\hline & Total & 3.25 & 0.95 & 3.11 & 0.96 & $5.79 *$ \\
\hline
\end{tabular}

Note: * Statistically significant at $\alpha$ level $<0.05$.

The level of parents' concern about their children at the beginning of the pandemic shown in Table 2 was higher than it was in the current period, with statistically significant differences in the total score and at the level of statements 2, 3, 5, 6, and 7. The worry about the child's safety in regards to being infected and the level of discomfort from the child's loss of care and assistance from specialists did not differ from the beginning of the pandemic to the current period, which was between a moderate to a high degree. When a parent was asked to interpret their level of worry due to the children's low level of understanding of the surrounding circumstances, $20 \%$ of parents responded "yes" when asked whether the child understands the existence of the coronavirus disease. Alternatively, $53.3 \%$ are unaware of the presence of the disease, and $26.8 \%$ are aware of it to some extent. Regarding the preventive measures taken in dealing with emerging conditions; $64.2 \%$ of parents responded that their child does not realize the meaning of social distancing, while $15.1 \%$ responded that their child understands it, and $20.7 \%$ responded that their child understands it to some extent. Of the respondents, $53.3 \%$ of parents responded that their child did not know how to maintain health safety conditions related to the prevention of coronavirus, compared to $17 \%$ of parents who responded that their child could; to a somewhat lesser extent, $29.7 \%$ of children are aware of how to maintain their health safety. 
The result of the second research question. "What are the sources of stress that affected parents in educating and training a child with disabilities at home due to the spread of the coronavirus?".

To determine the sources of stress that affected parents, which may explain the level of distress that accompanied the parents' condition during the spread of the Corona pandemic, the percentages were extracted for sources of stress in Table 3 and measured against differences according to the parents' academic qualification.

Table 3. The percentage of parents' endorsement of the sources of stress they suffer from and the differences according to their academic qualification.

\begin{tabular}{|c|c|c|c|c|c|c|c|}
\hline $\mathbf{N}$ & Items & Strongly Disagree \% & Disagree \% & Neutral \% & Agree \% & Strongly Agree \% & Chi-Square \\
\hline 1 & $\begin{array}{l}\text { Conflicting information on } \\
\text { the spread of the epidemic } \\
\text { from news sources and } \\
\text { social media }\end{array}$ & 4 & 8.3 & 28.1 & 31.9 & 27.6 & $32.03 *$ \\
\hline 2 & $\begin{array}{l}\text { No outside activities or } \\
\text { stimulating activities for } \\
\text { my child }\end{array}$ & 2.6 & 11.4 & 13.8 & 30.0 & 42.2 & $46.60 *$ \\
\hline 3 & $\begin{array}{l}\text { A lack of social meetings } \\
\text { between my child and } \\
\text { other children }\end{array}$ & 3.2 & 10.0 & 12.2 & 34.8 & 39.8 & $43.11 *$ \\
\hline 4 & $\begin{array}{l}\text { Feeling fearful and anxious } \\
\text { about any disease } \\
\text { symptoms that may } \\
\text { threaten my health or the } \\
\text { health of those around me }\end{array}$ & 2.2 & 4.7 & 11.1 & 35.5 & 46.5 & $26.38^{*}$ \\
\hline 5 & $\begin{array}{l}\text { Irregular sleep, eating, or } \\
\text { school schedule } \\
\text { for my child }\end{array}$ & 5.3 & 14.8 & 12.5 & 31.1 & 36.3 & 19.09 \\
\hline & Total & 3.46 & 9.84 & 15.54 & 32.66 & 38.48 & \\
\hline
\end{tabular}

Table 3 shows that most parents agree that the contents of the items are considered a source of psychological stress for them. $82 \%$ of parents, strongly agree and agree, felt worried and anxious about the symptoms that may threaten their health and those around them, followed by $74.6 \%$ who consider the lack of social meetings between their children with other children as a source of stress for them. $72.2 \%$ of the parents agreed that the absence of outside or motivational activities for the child represented a source of pressure on them.

The percentage of female agreement increased statistically on item 3 and 4 compared with males through the relationship that was examined between the gender of the parents and the responses on the categories of items 3 and 4, and it was shown that the value of the statistic chi-squared, for item $3, \chi^{2}(4, \mathrm{n}=623)=9.76$, sig $=0.04$. For item 4 , $\chi^{2}(4, \mathrm{n}=623)=9.69, \mathrm{sig}=0.04$ gender differences are not significant on other sources.

A statistically significant relationship appeared through chi-square, between parents' feeling of the first four sources of stress with their academic level. Parents with bachelor's degrees feel this pressure more than parents whose education level is less than a diploma or secondary school. Looking at the overall score, the stresses of parents with secondary education or below (Mean $=3.76$, Standard deviation $=0.78$ ) were less than the pressures felt by parents with a qualification of higher than secondary (Mean $=4.02$, Standard deviation $=0.70$ ) with a significant value of two independent-sample $t(621)=4.35$, sig $<0.001$.

Results of the third research question. What are the sources that the parents used to overcome the stress associated with the education and training of a child with disabilities at home due to the spread of the Coronavirus? The percentage of parents who used different sources to overcome the stress associated with teaching and training the child with disabilities at home and chi-square for the relationship with the parents' academic qualification is extracted in Table 4. 
Table 4. Percentage of parents using sources to handle stress and differences according to their academic qualification.

\begin{tabular}{|c|c|c|c|c|c|c|c|}
\hline No & Items & Never $\%$ & Rarely \% & Some Times $\%$ & Frequently \% & Always \% & Chi-Square \\
\hline 1 & $\begin{array}{l}\text { Reading scientific studies, books, or } \\
\text { magazines about dealing with } \\
\text { children with disabilities }\end{array}$ & 7.4 & 16.4 & 38.2 & 18.3 & 19.7 & $9.87 *$ \\
\hline 2 & $\begin{array}{l}\text { Browse blogs and websites for } \\
\text { information about my } \\
\text { child's disability }\end{array}$ & 2.9 & 10.9 & 35.0 & 25.5 & 25.7 & $12.87 *$ \\
\hline 3 & $\begin{array}{l}\text { Ask questions of specialists on } \\
\text { social media platforms }\end{array}$ & 13.3 & 20.2 & 34.7 & 16.9 & 14.9 & $12.85 *$ \\
\hline 4 & $\begin{array}{l}\text { Requesting help from the specialist } \\
\text { who follows up the child's case at } \\
\text { the center through phone calling or } \\
\text { WhatsApp }\end{array}$ & 16.7 & 17.3 & 35.0 & 18.8 & 12.2 & 0.46 \\
\hline 5 & $\begin{array}{l}\text { Follow the center's instructions and } \\
\text { instructions for families on how to } \\
\text { teach the child and deal with him } \\
\text { Communicating with families who }\end{array}$ & 9.0 & 11.1 & 33.1 & 25.2 & 21.7 & 7.28 \\
\hline 6 & $\begin{array}{l}\text { have a child with a disability like } \\
\text { my child's }\end{array}$ & 23.3 & 20.7 & 24.7 & 16.4 & 14.9 & $10.13 *$ \\
\hline 7 & $\begin{array}{l}\text { Watch YouTube videos about } \\
\text { "dealing with disabilities" that are } \\
\text { like my child's disability }\end{array}$ & 6.4 & 12.7 & 34.8 & 23.6 & 22.5 & 4.86 \\
\hline 8 & $\begin{array}{l}\text { Commitment to the goals set for my } \\
\text { child by the center that relates to the } \\
\text { individual educational program } \\
\text { and educational plan }\end{array}$ & 8.2 & 10.8 & 27.8 & 27.6 & 25.7 & 13.15 * \\
\hline 9 & $\begin{array}{l}\text { Follow TV programs that provide } \\
\text { information on children } \\
\text { with disabilities }\end{array}$ & 10.3 & 19.4 & 36.4 & 18.9 & 14.9 & 0.32 \\
\hline 10 & $\begin{array}{l}\text { Record videos or audio clips of my } \\
\text { child and share them with others of } \\
\text { your contacts }\end{array}$ & 21.5 & 16.9 & 30.3 & 16.5 & 14.8 & 5.31 \\
\hline
\end{tabular}

Note: * Statistically significant at $\alpha$ level $<0.05$.

The percentages in Table 4 show that parents use several sources in an attempt to overcome the pressure associated with educating and training children with disabilities at home. Of the respondents, $53 \%$ of the parents followed the plans previously set by the center for the child, with a statistically significant difference according to qualifications, $\chi^{2}$ $(8, n=623)=13.15$, favoring parents with qualifications higher than secondary compared with parents of secondary qualification or less. Furthermore, 51\% of parents reported surfing the Internet to obtain information about their child's disability, with a statistically significant difference according to their educational qualification, $\chi^{2}(8, \mathrm{n}=623)=12.87$, favoring parents with qualifications higher than secondary, and $46 \%$ of parents watched YouTube videos about dealing with similar disabilities to those of their child; the difference was not statistically significant according to their educational qualification. Generally, the diversity of the technology sources utilized by parents is evident and requires skills to navigate information and read from scientific sources related to children with disabilities.

Results of the fourth research question. How do parents evaluate the services they received from the special education centers during the Corona pandemic? Of the respondents, 59\% of parents expressed they are not receiving services at home, compared to $41 \%$ who received some services from the center, and $37 \%$ were satisfied with the center's services. Cross tabulation is extracted in Table 5 to examine the significance of the relationship between the overall satisfaction with the obtained actual services.

The percentages in Table 5 show that the level of satisfaction with the center increased in cases where the parents received services from the center, $\chi^{2}(4, n=623)=179.86$, sig $<0.05$. Additional analysis showed that people with higher qualifications were less satisfied with the services of the center. Findings from the satisfaction analysis require more attention from the responsible administrators to provide services in different times of emergencies, especially in cases of children who require more attention and care. 
Table 5. Level of satisfaction with the center according to the access of services.

\begin{tabular}{|c|c|c|c|c|c|c|}
\hline $\begin{array}{l}\text { Statement/Level } \\
\text { of Satisfaction }\end{array}$ & Never Satisfied & Not Satisfied & $\begin{array}{l}\text { Sometimes } \\
\text { Satisfied }\end{array}$ & Satisfied & Very Satisfied & $x^{2}$ \\
\hline \multicolumn{7}{|c|}{ Has your child received special education services from the center? } \\
\hline $\begin{array}{l}\text { My child has not } \\
\text { received services } \\
\text { while at home }\end{array}$ & $18.3 \%$ & $14.3 \%$ & $14 \%$ & $8.2 \%$ & $4 \%$ & \multirow{2}{*}{179.86 * } \\
\hline $\begin{array}{l}\text { Yes, my child has } \\
\text { received services } \\
\text { from the center }\end{array}$ & $0.6 \%$ & $3.7 \%$ & $8.3 \%$ & $16.1 \%$ & $12.5 \%$ & \\
\hline
\end{tabular}

Note: * Statistically significant at $\alpha<0.05$.

\section{Discussion}

From the first moments of declaring the spread of the coronavirus and considering it a pandemic, researchers' attention turned to the medical side to conduct examinations for the infected and test drugs and vaccines to limit the large spread of the virus and reduce its effects. Researchers' attention was then directed to psychological and behavioral issues and the social effects of the pandemic on members of society in general and on specific groups considered more vulnerable to infection risks. The current study is one of the few Arab studies that systematically explores the impact of the corona pandemic on parents of children with disabilities in terms of psychological fields and highlights the sources that helped them deal with their children while they ceased going to the special education center due to social distancing restrictions.

The study also included many parents of children suffering from intellectual disability, autism spectrum disorder, down syndrome, attention deficit hyperactivity, speech, and language disorders, in addition to other disorders that ranged from mild to severe. Some centers offer different types of remote support for parents and children; however, these interventions were relatively low and were accompanied by the emergence of some needs, including the desire for more support, care, and assistance at home, as well as orientation programs to address situations of worry and distress during the quarantine.

The results regarding the first research question indicated that parents suffer from different levels of worry about their children, and these feelings decreased over time; in general, these feelings decreased in the current period compared to the period at the beginning of the pandemic, but some feelings of discomfort, such as fear for the child from infection with the virus and the child's loss of care and assistance from specialists, are still at a high level since the start of the pandemic until the period of the study.

The results regarding the second research question showed that parental pressure has caused fear and anxiety about the emergence of disease symptoms that threaten their health and the health of their families, in addition to the negative impact of social isolation on the social development of their child, i.e., the lack of external and motivational activities has been a source of distress and pressure for parents.

The emergency and spread of infection cases provoke strong reactions of fear and preoccupation with the effects on physical and psychological health, especially with vulnerable groups, as stated in the study [19]. The study of Ren et al. [11] asserted that the state of anxiety among parents of children with disabilities during the coronavirus epidemic caused them to have psychological and behavioral problems and increased the pressure of parenting and social support. Many studies have agreed on the feelings of anxiety that afflicted families because of the corona pandemic, such as studies $[18,21]$

Parents reported difficulties in dealing with their children during the corona pandemic, which they considered normal situations as one of the main roles of the special education center, but under the circumstances of the pandemic, these services have entirely stopped, and the task has been transferred to the parents. This result is consistent with the study of Lee et al. [15], that the families were educating their children at home due to the 
pandemic, and that most of the families were exposed to anxiety and depression, and this was assured by $59 \%$ of parents who reported that their children did not receive special education services from the center and $41 \%$ of children received services that were provided remotely by the center's specialist, with varying levels of quality. This result is consistent with what Thorell et al. [16] yielded, namely that the pandemic has negative effects for homeschooling on families and their children, that there is a lack of support from schools, that communication with teachers was limited, and that reliance on parents in managing homeschooling led to high levels of stress, anxiety, domestic conflict, and social isolation.

The results suggest rebuilding the relationship between the parents, the center's administration, and the specialists so that parents have a more profound role in dealing with their children by qualifying them to implement and follow up the individual plan and by providing them with the necessary training in normal circumstances. It is also suggested to develop rehabilitation programs for the parents in anticipation of similar emergency conditions and to continue providing services in a way that supports parents role in dealing with their child at home. This is confirmed by the study of Kucharewucz and Wieteska [18], which stressed the need to provide more educational and counseling services to enable families of parents with children to deal with them. It explained the great importance of parent training, and Colizzi et al. [19] highlighted the importance of training parents of children with disabilities because they play multiple and wide roles.

The study also emphasized the need to support and assist parents in the fields of psychological, educational, and social service care and follow-up by specialists. Furthermore, the study emphasized the need to affirm by legislation what is related to the role of parents, considering them as part of the multidisciplinary team that prepares plans and develops educational and support programs for the child. The results of the study agree with Van Esch et al. [21], which indicated the importance of providing parents with adequate information about the condition of their children, support and encouragement, guidance, and direction, as well as on the cognitive aspects of the child's condition.

Findings regarding the third research question revealed the parent's own efforts, which helped him or her overcome the challenges in this emergency, such as browsing blogs and Internet sites to obtaining information and advice about their child's disability by watching YouTube videos explaining how to deal with cases like that of their child. The use of these resources was associated with the educational level of the parent.

Considering the new circumstances and the state of emergency that all parts of society have been exposed to, and the emergence of numerous attempts to fill the gaps in the lack of services provided, the new role assigned to a parent requires investigation and research. The new situation directs future studies to focus on the actual role of the parents in the handling of the child and to how the effect of electronic training and remote follow-up facilitates achieving the goals of the individual plan. This highlights the effectiveness of evidence and instructions that may be prepared in advance at the beginning of the school year, thereby considering emergency conditions that may occur in the future. This evidence considers the various contexts and circumstances according to the variables of the parent and the variables of the child with disabilities. The results of this study must be viewed considering some of the limitations of supportive services and challenges according to different disability groups or differences according to the gender of the children, especially since the main aim of the study was not to examine differences according to the gender of the child or the type of disability in response to the circumstances of the coronavirus pandemic.

Findings regarding the fourth research question showed a satisfaction increase in cases of parents received services from the center, suggesting the need for more attention from the administrators to provide services during emergencies, especially in cases of children who require more attention and care.

\section{The Limitation of the Study}

The limitations of this study come through the extent to which the sample represents parents who care for children of various disabilities and their severity and the number 
of responses received from parents of various nationalities in the participating countries. Parents who do not use smart devices were not represented here due to the difficulty of data collection by other means during the pandemic. The study was limited to the participation of parents who received invitations to participate in the study via open social networking sites or messages from teachers and departments of special education centers.

\section{Conclusions and Recommendations}

This study showed the impacts of the corona pandemic on parents of children with disabilities who took full supervision in the absence of support services directed to their children. Although a few centers have continued to provide remote services to children, this was not sufficient to meet needs nor provide the care these children and families deserved. The new circumstances require paying attention to training parents and involving them in advance in all activities, as well as highlighting the need for individual plans as preparation for such events in the future.

The study recommends the necessity to provide clear written instructions and directions to parents and to provide visual recordings showing various methods for educating children with disabilities. In particular, this study recommends the use of speech training sessions, movement training sessions, models of methods for strengthening the child, models for modifying behavior to meet the care and support required at home, activating distance learning platforms, and training parents to use them. The study also recommends providing guidance programs to deal with situations of discomfort and distress during quarantine that take into consideration the different educational levels, implementing measures and procedures during the interruption of direct work at the center, publishing protocols regarding methods for implementing and monitoring the progress of children with disabilities, and teaching parents' ways to obtain psychological support from websites.

Author Contributions: Conceptualization, F.A. and I.A.; methodology, F.A. and A.R.; software, F.A.; validation, I.A. and Z.A.; formal analysis, F.A.; investigation, D.K.; resources, D.K. and A.A.; data curation, F.A. and A.R.; writing-original draft preparation, F.A. and I.A.; writing-review and editing, D.K. All authors have read and agreed to the published version of the manuscript.

Funding: This research received no external funding.

Institutional Review Board Statement: The study was conducted according to the guidelines of the Declaration of Helsinki, and approved by the Institutional Review Board.

Informed Consent Statement: Informed consent was obtained from all subjects involved in the study.

Data Availability Statement: Not applicable.

Conflicts of Interest: The authors declare no conflict of interest.

\section{References}

1. WHO. Coronavirus Disease (COVID-19) Dashboard. 25 June 2020. Available online: https://www.who.int/docs/default-source/ coronaviruse/situation-reports/20200625-covid-19-sitrep-157.pdf?sfvrsn=423f4a82_2 (accessed on 15 April 2021).

2. Amirah-Fernández, A. Coronavirus in Arab Countries: Passing Storm, Opportunity for Change or Regional Catastrophe? Elcano Royal Institute 2020, ARI 37/2020 (English Version). 6 April 2020. Available online: http:/ / www.realinstitutoelcano.org/wps / portal/rielcano_en (accessed on 1 March 2021).

3. Dong, C.; Cao, S.; Li, H. Young children's online learning during COVID-19 pandemic: Chinese parents' beliefs and attitudes. Child. Youth Serv. Rev. 2020, 118, 105440. [CrossRef] [PubMed]

4. Courtenay, K.; Perera, B. COVID-19 and people with intellectual disability: Impacts of a pandemic. Ir. J. Psychol. Med. 2020, 37, 231-236. [CrossRef] [PubMed]

5. Narzisi, A. Handle the Autism Spectrum Condition During Coronavirus (COVID-19) Stay At Home period: Ten Tips for Helping Parents and Caregivers of Young Children. Brain Sci. 2020, 10, 207. [CrossRef] [PubMed]

6. Zablotsky, B.; Bradshow, C.; Stuart, E. The association between mental, stress, and coping supports in mothers of children with autism spectrum disorders. J. Autism Dev. Disord. 2013, 34, 1380-1393. [CrossRef] [PubMed]

7. Hsiao, Y. Parental stress families of children with disabilities. Interv. Sch. Clin. 2017, 53, 201-205. [CrossRef]

8. Mcstay, R.; Trembath, D.; Dissanayake, C. Stress and family's quality of life in parents of children with autism spectrum disorder: Parent gender and the double ABCX model. J. Autism Dev. Disord. 2018, 44, 3101-3118. [CrossRef] [PubMed] 
9. Liu, X.; Kakade, M.; Fuller, C.J.; Fan, B.; Fang, Y.; Kong, J.; Guan, Z.; Wu, P. Depression after exposure to stressful events: Lessons learned from the severe acute respiratory syndrome epidemic. Compr. Psychiatry 2012, 53, 15-23. [CrossRef] [PubMed]

10. Crnic, K.; Low, C. Everyday stresses and parenting. In Handbook of Parenting, Volume 5: Practical Issues in Parenting, 2nd ed.; Bornstein, M.H., Ed.; Lawrence Earlbaum: Mahwah, NJ, USA, 2002; pp. 243-268.

11. Ren, J.; Li, X.; Chen, S.; Chen, S.; Nie, Y. The Influence of Factors Such as Parenting Stress and Social Support on the State Anxiety in Parents of Special Needs Children During the COVID-19 Epidemic. Front. Psychol. 2020, 11, 565393. [CrossRef] [PubMed]

12. Hauser-Cram, P.; Warfield, M.; Shonkoff, J.; Krauss, M.; Sayer, A.; Upshur, C.; Hodapp, R. Children with Disabilities: A Longitudinal Study of Child Development and Parent Well-Being. Monogr. Soc. Res. Child Dev. 2001, 66, I-126. Available online: http:/ / www.jstor.org/stable/3181571 (accessed on 1 March 2021).

13. Woodman, A.C.; Mawdsley, H.P.; Hauser-Cram, P. Parenting stress and child behavior problems within families of children with developmental disabilities: Transactional relations across 15 years. Res. Dev. Disabil. 2015, 36C, 264-276. [CrossRef] [PubMed]

14. Brooks, S.K.; Webster, R.K.; Smith, L.E.; Woodland, L.; Wessely, S.; Greenberg, N.; Rubin, G.J. The psychological impact of quarantine and how to reduce it: Rapid review of the evidence. Lancet 2020, 395, 912-920. [CrossRef]

15. Lee, S.J.; Ward, K.P.; Olivia, C.D.; Downing, K.M. Parenting activities and the transition to home-based education during the COVID-19 pandemic. Child. Youth Serv. Rev. 2021, 122, 105585. [CrossRef] [PubMed]

16. Thorell, L.B.; Skoglund, C.; de la Peña, A.G.; Baeyens, D.; Fuermaier, A.B.; Groom, M.J.; Mammarella, I.C.; Van der Oord, S.; van den Hoofdakker, B.J.; Luman, M.; et al. Parental experiences of homeschooling during the COVID 19 pandemic: Differences between seven European countries and between children with and without mental health conditions. Eur. Child Adolesc. Psychiatry 2021. [CrossRef] [PubMed]

17. Chen, S.; Chen, S.; Li, X.; Ren, J. Mental Health of Parents of Special Needs Children in China during the COVID-19 Pandemic. Int. J. Environ. Res. Public Health 2020, 17, 9519. [CrossRef] [PubMed]

18. Kucharewucz, J.; Wieteska, A. The role of social support in achieving mental well-being for parents of disabled children. Organ. Manag. Ser. 2019, 141, 231-238. [CrossRef]

19. Van Esch, L.; O’Nions, L.; Hannes, K.; Ceulemans, E.; Van Leeuwen, K.; Noens, I. Parenting early adolescents with autism spectrum disorder before and after transition to secondary school. Adv. Neurodev. Disord. 2018, 2, 179-189. [CrossRef]

20. Colizzi, M.; Sironi, E.; Antonini, F.; Ciceri, M.; Bovo, C.; Zoccante, L. Psychosocial and Behavioral Impact of COVID-19 in Autism Spectrum Disorder: An Online Parent Survey. Brain Sci. 2020, 10, 341. [CrossRef] [PubMed]

21. Alhuzimi, T. Stress and emotional wellbeing of parents due to change in routine for children with Autism Spectrum Disorder (ASD) at home during COVID-19 pandemic in Saudi Arabia. Res. Dev. Disabil. 2021, 108, 103822. [CrossRef] [PubMed]

22. Esentürk, O. Parents' perceptions on physical activity for their children with autism spectrum disorders during the novel Coronavirus outbreak. Int. J. Dev. Disabil. 2020, 66, 1-13. [CrossRef] 